\title{
A GOVERNANÇA NA POLÍTICA \\ NACIONAL DE REGIONALIZAÇÃO DO TURISMO: ESTUDO DOS \\ GRUPOS GESTORES DOS DESTINOS INDUTORES DO CEARÁ
}

GOVERNANCE IN THE NATIONAL TOURISM REGIONALIZATION POLICY: STUDY OF MANAGEMENT GROUPS OF THE INDUCTOR DESTINATIONS OF CEARÁ

LA GOBERNANZA EN LA POLÍTICA NACIONAL DE REGIONALIZACIÓN DEL TURISMO: ESTUDIO DE LOS GRUPOS GESTORES DE LOS DESTINOS INDUCTORES DE CEARÁ

Laura Mary Marques Fernandes Prof. $^{a}$ do Mestrado em Gestão de Negócios Turísticos da UECE e Prof. $^{a}$ do Curso de Gestão de Turismo da Faculdade Ateneu. lauralucas66@hotmail.com

\section{Luzia Neide Menezes Teixeira Coriolano}

Universidade Estadual do Ceará - UECE.

luzianeidecoriolano@gmail.com

Data de Submissão: 15/07/2014

Data de Aprovação: 15/06/2015

Resumo: A política nacional de regionalização do turismo promoveu a definição de destinos indutores do desenvolvimento turístico regional e a implantação de instâncias de governança denominadas grupos gestores. Este artigo trata do desempenho da política na efetivação da governança por meio dos grupos gestores que têm o objetivo de coordenar o processo de regionalização e toma como objeto empírico as instâncias de governança dos destinos indutores do Ceará: Fortaleza, Aracati, Jijoca de Jericoacoara e Nova Olinda. Os estudos sobre governança não restringem o entendimento do termo à organização interna das empresas e avançam na descrição das diversas formas pelas quais as sociedades se organizam na busca de objetivos. É esta acepção a utilizada na política de regionalização. As literaturas relativas à governança e as concepções teóricas sobre a intencionalidade dos processos de governança são distintas. A pesquisa contempla revisão de literatura, pesquisa documental e de campo. O público entrevistado é composto por representantes dos grupos gestores que são tripartites. No Ceará, os grupos gestores não ganham impulso, não conseguem estabelecer 
vínculos fortes entre si e com as forças políticas. A criação dos grupos movimentou os locais, mas os grupos não se sustentaram. A condição de decidir e de interferir foi insuficiente e descontínua.

Palavras-chave: Governança. Grupo gestor. Destino indutor.

\begin{abstract}
The national tourism regionalization policy promoted the definition of inductor destinations of regional tourism development, and the deployment of governance called management groups. This article addresses the performance of the policy in the execution of governance, through management groups aimed at coordinating the process of regionalization. It takes, as its empirical object, the instances of governance of the inductor destinations of Ceará: Fortaleza, Aracati, Jijoca de Jericoacoara and Nova Olinda. Studies of governance do not restrict the understanding of the term to the internal organization of companies, but also describe the different ways in which societies organize themselves in pursuit of their goals. This is the definition used in the regionalization policy. The literature on governance, and the theoretical concepts of the intentionality of governance processes, are distinct. The research includes a published literature, documents, and field research. The interviewee audience is composed of representatives of management groups that are tripartite. In Ceará, the management groups failed to establish strong ties with each other and with the political powers. The creation of groups motivated the locations, but the groups were not sustained. The condition of deciding to interfere fell short, and was discontined.
\end{abstract}

Keywords: Tourism. Governance. Inductor destination.

Resumen: La política nacional de regionalización del turismo promovió la definición de destinos inductores del desarrollo turístico regional y la implantación de instancias de gobernanza denominadas grupos gestores. Este artículo trata del desempeño de la política en la ejecución de la gobernanza por medio de los grupos gestores que tienen el objetivo de coordinar el proceso de regionalización, y toma como objeto empírico las instancias de gobernanza de los destinos inductores de Ceará: Fortaleza, Aracati, Jijoca de Jericoacoara y Nova Olinda. Los estudios sobre gobernanza no restringen la comprensión del término a la organización interna de las empresas y avanzan en la descripción de las diversas formas a través de las cuales las sociedades se organizan en busca de sus objetivos. Esta es la acepción utilizada en la política de regionalización. Las literaturas relativas a la gobernanza y a las concepciones teóricas sobre la intencionalidad de los procesos de gobernanza son distintas. La investigación contempla revisión de literatura, investigación documental y de campo. El público entrevistado estaba compuesto por representantes de los grupos gestores, que son tripartitos. En Ceará los grupos gestores no ganan impulso, no logran establecer vínculos fuertes ni entre sí, ni con las fuerzas políticas. La creación de los grupos dio movimiento a los locales, pero los grupos no se sustentaron. La condición de decidir y de interferir fue insuficiente y discontinua.

Palabras clave: Gobernanza. Grupo gestor. Destino inductor.

INTRODUÇÃO

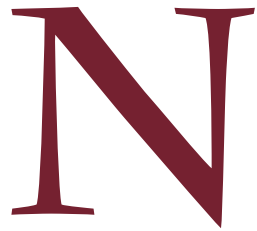
as últimas décadas ocorreram mudanças nos setores público e privado, surgem novos sujeitos e novos arranjos Os sujeitos sociais se diversificam e assumem posições, alterando o espaço público. Associações, comitês e grupos se fortalecem politicamente. Emergem organizações 
ISSN: 1983-7151

não governamentais (ONGs) e formas de associativismo. Surgem instituições internacionais com características supranacionais, como a Organização Mundial do Comércio (OMC) e a Comunidade Europeia. Teóricos discutem a centralidade dos Estados no sistema internacional e a autonomia política. Pesquisas em diversos contextos e escalas têm destacado a necessidade e a exequibilidade de processos de gestão que fortaleçam a organização social por meio de conselhos e associações civis na busca de políticas que atendam aos interesses da população.

Além da inserção das comunidades na organização local e na participação efetiva na construção de políticas públicas, surgem grupos com iniciativas contra hegemônicas, a exemplo do turismo de base comunitária, que age e não espera a ação dos governos. O poder diz respeito às relações de força e não se restringe ao Estado, assim a sociedade civil também tem condições de exercer poder. A articulação horizontal dos sujeitos sociais nos municípios e nas formas intermunicipais de gestão se apresenta como nova orientação. São consórcios municipais de saúde, comitês de bacias hidrográficas, conselhos regionais de desenvolvimento. O reformismo no Brasil incorporou ideias do discurso democrático em geral: descentralização, participação e cidadania. Descentralizar confude-se com democratização, assim democráticos seriam entes e espaços descentralizados diminuindo o espaço do Estado. Os governos alteram a forma de atuação, buscam ser mais eficientes, mesmo assim as políticas públicas apresentam resultados insatisfatórios, não conseguem universalizar no Brasil o acesso à moradia, à educação, à saúde e ao saneamento e, muito menos, viabilizar o lazer para a maior parte da população brasileira.

Surge a palavra governança na política nacional de regionalização do turismo com a proposta de criação de instâncias de governança regionais e locais. Essas últimas, objeto desta pesquisa, denominadas de grupos gestores dos destinos indutores do desenvolvimento turístico regional, instituídas com o objetivo de realizar articulação com representantes do poder público, iniciativa privada e terceiro setor para execução das ações voltadas ao desenvolvimento do turismo propostas por ocasião do Seminário de Competitividade; garantir a existência de um grupo local; levantar todos os projetos em desenvolvimento ou em fase de proposição no município e verificar se as ações propostas no seminário foram solicitadas de forma a direcionar os esforços para execução. 
Esta pesquisa teve como objetivo identificar o desempenho dos grupos gestores dos destinos indutores do Ceará na condução do processo de regionalização. Contemplou revisão de literatura, pesquisa documental e de campo. A amostra é do tipo não probabilística "intencional", composta por sujeitos representativos, pois a escolha levou em conta os sujeitos ligados à governança no turismo. Contemplou 42 representantes que participaram ou ainda compõem os grupos gestores dos destinos indutores no período de 2008 a 2013. Participaram lideranças de diferentes segmentos, permitindo que fossem obtidas informações com sujeitos ligados a diferentes instituições e não somente com o coordenador do grupo gestor, tais como: representantes das Secretarias Municipais, cursos de turismo, conselhos comunitários, associações profissionais e comunitárias, universidades, ex-integrantes de órgãos públicos e empresários. Passo importante foi a observação in loco feita por meio da participação em reuniões e de visitas aos destinos indutores do desenvolvimento regional nos anos de 2012 e 2013. Após a transcrição, os dados da pesquisa de campo foram analisados e interpretados. Na interpretação de mensagens é "importante lembrar que o analista científico é um intérprete", portanto "faz uma leitura também discursiva influenciada pelo afeto, posição, crenças, experiências e vivências; portanto, a interpretação nunca será absoluta e única, pois também produzirá seu sentido" (CAREGNATO; MUTTI, 2006). A abordagem qualitativa ajuda a chegar à compreensão da realidade entendida como totalidade. $\mathrm{Na}$ elaboração do suporte teórico foi priorizado como base para entendimento do tema e do desenvolvimento do artigo o conceito de governança.

\section{GOVERNANÇA: PANORAMA CONCEITUAL E PERSPECTIVA DA POLÍTICA NACIONAL DE REGIONALIZAÇÃO DO TURISMO}

O processo de democratização e de descentralização da gestão pública no Brasil, a partir da Constituição de 1988, cria ambiente favorável para que se construam socialmente instâncias autônomas com o objetivo de fortalecer a capacidade organizacional da sociedade. A governança assume o papel de estratégia na condução das políticas públicas. O debate sobre governança como compartilhamento de poder só é possível em ambiente democrático, o 
que, no entanto, não é garantia de efetivação. A democracia é processo, um jogo dialético de forças e poder. O Estado se reestrutura com o objetivo de "ser capaz de continuar a ser veículo viável na busca do interesse coletivo em uma era de globalização da economia e do aumento da dinâmica institucional e subnacional." O que explica contar cada vez mais "com instrumentos de política bastante sutis em seu intercâmbio com a sociedade, mas isso não significa necessariamente que ser menos eficiente nas técnicas coercitivas de direção" (PIERRE; PETERS, 2000, p. 196).

O estabelecimento das instâncias de governança locais - os grupos gestores dos destinos indutores do desenvolvimento turístico regional - exige participação nos debates e na construção dos espaços de governança, pois só se concretiza com a participação direta. O acesso ao voto não garante ao cidadão governos democráticos. Assim a proposta de governança na política de turismo demanda mudança na forma de a sociedade e de o Estado atuarem. No entanto, afirma Nogueira (2004, p. 54) que "Aliviando-se de parte da carga, o Estado incentiva o envolvimento subnacional (local e regional, sobretudo)." A descentralização, no entanto, seria elemento de fortalecimento do Estado, uma vez que a dinâmica esperada seria solidária. Suscita participação, cidadania e sociedade civil, contudo a concepção é de cooperação. "A sociedade civil locus de cidadãos organizados - passaria a ser ambiente propício para uma participação convertida em movimento de maximização de interesses e/ou de colaboração governamental" (NOGUEIRA, 2004, p. 54-57). Nesse ambiente, o Estado apresenta iniciativas de descentralização e democratização alterando a forma de governar com as ideias de New Public Management e governança. Peters e Pierre (1998, p. 232) afirmam que governança é uma teoria política e a New Public Management (NPM) uma teoria organizacional. Que "governança é sobre o processo, enquanto NPM é sobre resultados".

A noção de governança altera a maneira de agir na administração pública, mas só se efetiva quando o ato de governar estabelece um tipo de relação democrática entre Estado e sociedade. Esta é a noção de governança que se considerou ao analisar os grupos gestores dos destinos indutores. No entanto, o termo governança tem sido entendido de diferentes formas desde seu surgimento nos anos 1930, com a publicação de The Nature of the Firm de 
Ronald Coase. O autor aborda o termo como processos pelos quais a firma se organiza para alcançar ação mais eficaz, nessa perspectiva é entendida como a coordenação interna de uma empresa que atua com o objetivo de reduzir custos (LORRAIN, 1982). Nos anos 1980, o termo se desenvolve na literatura de negócios nos Estados Unidos como governança corporativa, e no final do período é incorporado à ciência política inglesa no Programa Economic and Social Research Council (ESRC) financiado pelo governo. De modo geral, governança corporativa se insere no processo de tomada de decisão, definição de regras nas empresas e na diminuição dos problemas.

A governança corporativa diz respeito à gestão das organizações e à relação com acionistas - shareholders - e outras partes interessadas - stakeholders, ou seja: clientes, funcionários, fornecedores e comunidades. Envolve solução para o conflito de agência, decorrente da assimetria informacional e do conflito de interesses entre as partes envolvidas: proprietários e administradores. As práticas de governança corporativa se desenvolvem na primeira metade dos anos 1990, época em que, especialmente nos Estados Unidos, os acionistas de diversas sociedades empresárias identificam a necessidade de estabelecer regras que os protegessem. Governança corporativa diz respeito também às regras que orientam o relacionamento na companhia na busca de fazer convergir interesses de acionistas controladores, acionistas minoritários e administradores. As definições de governança corporativa enfatizam práticas de boas políticas que promovam a proteção das partes interessadas em uma sociedade, mitigando conflitos. A governança corporativa na gestão pública é entendida como a gestão das "agências do setor público, por meio dos princípios de governança corporativa do setor privado" [...] (MATIASPEREIRA, 2010, p.73-74). No Brasil, o tema ganha importância devido aos grandes conglomerados, efeitos da privatização e da importação de regras globais. Com a substituição das firmas hierarquizadas e integradas verticalmente por organizações globais e em rede, a governança corporativa é assimilada pelo setor público em vários países e o termo governança passa a ser aplicado ao poder e às organizações locais (MILANI; SOLINIS, 2002). A expressão migra do mundo empresarial e passa a ser aplicada nas organizações locais.

Os estudos sobre governança não restringem o entendimento do termo à organização interna das empresas, com o intuito de reduzir custos, e como meio 
ISSN: 1983-7151

de proteção dos acionistas avançam na descrição das diversas formas pelas quais as sociedades se organizam na busca de objetivos que podem ser voltados ao meio ambiente, ao turismo e também em diferentes escalas: mundial, regional e local. As literaturas relativas à governança são distintas. No final dos anos 1980, o termo governance reaparece nos documentos do Banco Mundial, significando a forma como o país gerencia recursos econômicos e sociais na promoção do desenvolvimento, concepção pautada no gerenciamento. Dessa forma, o importante era "responsabilizar a incompetência institucional dos Estados em desenvolvimento pelos fracassos constatados na implementação dos Programas de Ajuste Estrutural - PAS, ou seja, um conjunto de reformas macroeconômicas e setoriais julgadas indispensáveis para a abertura generalizada dos mercados." Essa foi a tônica do discurso da cooperação internacional em geral, que definiu como necessária a reforma das administrações dos países do Sul para melhor responder às exigências da eficácia e da rentabilidade economicistas inerentes aos Programas de Ajuste Estrutural (PAS). Consequentemente, foram realizados vários programas nacionais de reforma do Estado - programas nacionais de "boa governança"- na África, na Ásia e na América Latina. Os programas geralmente acompanhados de políticas de descentralização e de formação às técnicas do "New Public Management" (MILANI; SOLINÍs, 2002, p.271).

A boa governança entra na agenda internacional com o objetivo de direcionar as políticas públicas dos países que recebiam ajuda das agências internacionais. Torna-se condição para o apoio político e econômico e também objetivo para os países em desenvolvimento. Assim, na perspectiva da teoria do desenvolvimento, "boa governança" diz respeito à forma de governar, como se exerce o poder na administração dos recursos. O problema é apresentado como conjuntural e não estrutural, como se a gestão pudesse solucionar os problemas inerentes ao modo de produção capitalista. $O$ termo boa governança utilizado pelo Banco Mundial diz respeito "à eficácia dos serviços públicos, à privatização das empresas estatais, ao rigor orçamentário e à descentralização administrativa" (MATIAS-PEREIRA, 2010, p.73).

O interesse da literatura acadêmica na governança se origina com os cientistas sociais atentos à mudança na maneira de governar (STOKER, 1998; DE LOË, 2009). Governança é tema que vem sendo objeto de pesquisa científica. 
Na perspectiva da ciência política, governança se refere não só à questão de estrutura administrativa, mas, principalmente, ao modo e sentido de governar. Stocker (1998, p.2) argumenta: "a essência da governança é o foco em mecanismos que não repousam no recurso à autoridade e sanções do governo", ou seja, é resultante de outro tipo de interação entre Estado e outros atores públicos. Governança como compartilhamento de poder significa que a participação não se restringe ao apoio das decisões vindas dos governos, mas ocorre quando há participação dos sujeitos envolvidos nas decisões. Nessa perspectiva, há implicações na democratização, significa estabelecer relações mais próximas entre Estado e outros agentes sociais, o que se coaduna com a proposta de regionalização no turismo na qual são definidos grupos gestores nos destinos indutores. É modelo cujo Estado interage com atores locais. Esse modelo tende a atender às demandas locais ao inserir sujeitos locais no processo decisório, apesar de apresentar também limitações e obstáculos. O termo governança implica participação e poder de decisão. Ahrens $(2006$, p.7) explicita que a organização da governança "é composta de arranjos institucionais e processos políticos de formulação e implementação de objetivos políticos e refere-se à coordenação dos diversos atores públicos e do setor privado." Explica que "a estrutura de governança apresenta características de um bem coletivo, constituído por vários atores que influenciam a formulação de políticas tanto de cima para baixo top-down quanto de baixo para cima." E que "Geralmente, o Estado é o ator principal e mais poderoso devido ao poder coercitivo e a capacidade de criação e empoderamento de instituições." (AHRENS, 2006, p.7).

Diante dos diferentes entendimentos sobre governança, Frey (2007, p.138) afirma que há "uma mudança substancial - tanto em política urbana quanto em teoria urbana - dos conceitos tradicionais, baseados no princípio da autoridade estatal, para abordagens de governança." A ênfase é nas "tendências de gestão compartilhada e interinstitucional que envolve o setor público, o setor produtivo e o crescente terceiro setor." Na política de regionalização do turismo, a governança é relacionada à "descentralização do poder de decisão, com base na gestão democrática, a partir da participação social" (MTur, 2007, p. 16). Em que pesem as deficiências do Estado em criar condições favoráveis à população, a governança no setor público assume concepções com diferentes nuances voltadas: às questões gerenciais, aos procedimentos e às questões 
democráticas envolvendo a participação. Dessa forma, "É possível distinguir entre versões de governança que enfatizam [...] o aumento da eficiência e efetividade governamental, e outros que focalizam [...] o potencial democrático e emancipatório de novas abordagens de governança" (FREY, 2007, p.139). Portanto, pode-se afirmar que a governança no setor público está associada também a uma mudança na forma de gerir: o Estado assume posição relevante, mas também se adequa aos novos atores. Na escala local, a governança promove aproximação e cooperação entre cidadãos, empresas e entidades sem fins lucrativos na condução de suas ações. Assim, politicamente, o conceito de governança aparece em contraste à visão monolítica de Estado, como entidade natural e expressão unificada de uma nação (BEVIR, 2011). Na regionalização do turismo a presença do Estado é permanente, há um sistema nacional na estruturação da proposta de governança e o Estado tem representação na instância de governança.

Governança também significa aquisição e distribuição do poder na sociedade, ao passo que governança corporativa restringe-se à forma como as corporações são administradas. Governança é termo ligado à elaboração e à implementação de políticas públicas como no modelo proposto pela regionalização no turismo, no entanto, a palavra governança é definida a partir de diversos enfoques e assume uma variedade de significados. Esclarece Stocker (1998) que, em relação ao uso tradicional de governança e seu significado no dicionário, 0 termo é definido como sinônimo de governo, no entanto, no trabalho crescente sobre governança há redirecionamento na utilização, pois governança é entendida como "mudança no sentido do governo, referindo-se a um novo processo de governar." Há, no entanto, afirma Stocker (1998), concordância em relacionar governança ao desenvolvimento de estilos de governar em que as fronteiras entre e dentro dos setores público e privado tornaram-se tênues. Na regionalização do turismo, governança é governo, proposta de um estilo de governo democrático, com participação direta da sociedade.

Na análise de Kersbergen \& Waarden (2004, p.143-144), ocorrem mudanças nas formas, nos mecanismos e nos estilos de governança. Essas mudanças têm sido objeto de uma variedade de literaturas e disciplinas, incluindo Ciência Política, Direito, Administração Pública, Economia, Negócios, Administração 
e Sociologia, bem como Geografia e História e assim o termo "governança" recebe significados diferentes nas literaturas dessas diversas áreas. Os autores (2004) elencam significados de governança a partir de Hirst (2000), Rhodes (1997, 2000) Pierre \& Peters (2000), entre eles estão "Boa governança", utilizado pelo Banco Mundial e outras organizações internacionais como a Organização para a Cooperação Econômica e Desenvolvimento (OCDE). Outro sentido é proveniente da teoria das relações internacionais que se refere à possibilidade de governar sem governo. Conforme Kersbergen e Waarden (2004), a literatura tem apontado para a possibilidade de cooperação entre os Estados-nação em um sistema internacional, que à primeira vista, não é propício para essa cooperação, assim organizações internacionais, regimes e tratados são vistos como novas formas de governança internacional para lidar com problemas tipicamente transnacionais. Outro sentido de governança sem governo é o de auto-organização das sociedades e das comunidades, além do mercado e do estado. Os autores citam Elinor Ostrom (1990), que estudou a capacidade das comunidades em diferentes lugares e épocas para gerir recursos comuns e prevenir seu esgotamento e identificaram que pequenas comunidades locais o fizeram sem ajuda de um governo formal, mas por meio do autogoverno de baixo para cima por associações, entendimentos informais, negociações, regulamentos, relações de confiança e controle social informal em vez de coerção estatal (2004).

Stocker (1998) desenvolve arcabouço teórico sobre governança, do qual se depreende que o tema se insere na forma como os problemas são administrados e refere-se não apenas aos governos, mas também aos representantes da sociedade civil. Com origem relacionada às mudanças ocorridas no Estado durante as últimas décadas, corresponde ao desenvolvimento de marco teórico diante da sociedade contemporânea que mudou social, política e economicamente. Governança na ciência política vai além da perspectiva administrativa. A capacidade dos governos de governar aumentou com as concepções da New Public Management e da governança, contribuindo na adoção de meios na busca de mais eficiência na ampliação da autonomia de atores como governos locais, agências ou redes que interligam agentes públicos e privados. Vários autores afirmam que governança não é tema novo. 
Kooiman (2003) esclarece que o tema como conceito não é novidade, pois tem sido tratado mais sistematicamente e há grande espaço para surgir um paradigma de governança. Davies (2011) cita os autores Fairlie (1926), White (1945) e Fisher (1972), que estudaram diferentes formas de participação de representantes públicos no Reino Unido e nos Estados Unidos demonstrando a colaboração entre Estado e cidadão para afirmar que governança não é tema novo.

Davies (2011) argumenta que, se as redes de governança são promovidas em um contexto no qual estruturas tradicionais e conflitos não foram suplantados, se existem em uma totalidade contraditória com instabilidade crônica, concentração de poder e riqueza, e competição intensa esse contexto, leva também a considerar a possibilidade que a mediação das instituições se dá por essas condições. Isso explicaria, por exemplo, o porquê do êxito de redes compreendidas por atores poderosos com dotes material e cultural similares e interesses congruentes (como comunidades políticas) que parecem mais propensos a florescer. Esse aspecto é muito importante na análise dos grupos gestores, pois como garantir a igualdade entre diversos sujeitos, principalmente, para aqueles com menor poder político e econômico nos grupos gestores do Ceará? A regionalização do turismo apresenta um sistema de coordenação de cima para baixo e demanda funcionamento de baixo para cima. Davies (2011) questiona "a viabilidade de se forjar objetivos comuns entre atores desiguais e afirma que a situação tende a ser insustentável enquanto as condições do capitalismo subsistirem" (2011, p.132). Menciona que a "rede busca mobilizar recursos e inscrever cidadãos ativistas, mas com sucesso limitado, levando a governamentalização" (2011, p. 132). O que se verifica nos grupos gestores é que a coordenação em rede por meio das instâncias de governança ainda está em uma fase na qual os grupos não conseguiram se autogerenciar e o Estado não tem conferido poder aos grupos gestores.

Como explica Davies (2011), no mundo social pode-se trabalhar com a estrutura social existente ou confrontá-la e não existe razão teórica a priori que negue a possibilidade da transformação das estruturas da sociedade. $O$ autor explica que entender que a relação entre as instituições e a estrutura é dialética pode supor que as instituições que estão igualitárias, democráticas e orientadas coletivamente são susceptíveis de ser insustentáveis, desde que as 
condições sociais do capitalismo subsistam (DAVIES, 2011). O estudo dos grupos gestores dos destinos indutores é estudo empírico da concepção de governança de essência reformista. A essência transformadora da sociedade está na inserção de representantes da população residente na busca de desenvolvimento por meio do turismo. Esse empoderamento da sociedade, mesmo que situado na agenda neoliberal em longo prazo é incompatível com o modo de produção vigente. Davies (2011) cita que Riedel questionou os mecanismos de governança participativa, os grupos de controle de comunidade e a falsa expectativa que os governos se rendem. Contudo, considera que a "onipresença histórica de redes de governança por elas mesmas não diz nada sobre as relações de poder que encarnam, hierárquicas ou de outra forma, a sua autenticidade ou veículos para inclusão democrática" (2011, p.56). Portanto, as experiências de governança precisam ser estudadas caso a caso, é o que se faz nesta pesquisa, por exemplo.

A concepção de governança avança e passa por diferentes explicações: ideia da perda de centralidade do poder do Estado, aumento da rede de governança e retorno do Estado como o orquestrador de metagovernance. Jessop apud Davies (2011) defende que o Estado não é mais a autoridade soberana, tornouse menos hierárquico, menos centralizado e define metagovernance como a governança do governo mais governança (2004, p. 52). Autores que são expoentes da teoria da governança, como Bevir, Rhodes e Stocker, alteram as próprias concepções sobre governança e afirmam que não há uma única teoria da governança contemporânea (DAVIES, 2011). Ao estudar governança por meio da hegemonia a partir da perspectiva de Gramsci, Davies (2011), considera que o desafio é compreender o propósito de conexões e as relações de poder. A reprodução da desigualdade de poder pode existir dentro das próprias instâncias de governança, as áreas mais bem articuladas entre si e com os poderes políticos econômicos podem obter mais vantagens. O Estado pode alterar os rumos dos projetos, concedendo protagonismo a este ou àquele segmento. O bom funcionamento de uma instância pode significar apoio do Estado, mas não, necessariamente, autogestão.

Relacionando governança com desenvolvimento, Dallabrida (2007, p. 6) utiliza o termo governança territorial designando-o como "as iniciativas ou ações que expressam a capacidade de uma sociedade organizada territorialmente, para 
gerir os assuntos públicos a partir do envolvimento conjunto e cooperativo dos atores sociais, econômicos e institucionais". Para o autor (2007), o exercício da governança territorial ocorreria pela atuação dos diferentes atores, nas instituições, incluindo o Estado, e organizações da sociedade civil. Governança é conceito-chave nas políticas. É estratégia para conduzir o governo e, portanto, as políticas públicas, envolvendo diversos atores e é teoria política, pois descreve certo tipo de relação entre o Estado e a sociedade (PETERS; PIERRE, 1998). Multiplicam-se as concepções de governança e existe uma crescente literatura sobre a influência das organizações supranacionais na governança do turismo, bem como das organizações não governamentais (HALL, 2011). Hall (2011) avalia que não há definição única aceita sobre governança, no que cita Kooiman (2003, p. 4), que entende governança como "a totalidade das concepções teóricas em governar" (HALL, 2011, p. 3).

O conceito de governança neste trabalho tem na sua base o deslocamento da autoridade com o compartilhamento das decisões e a descentralização do processo decisório, pois se entende que governança refere-se ao domínio que os sujeitos em um dado território podem exercer. Na escala regional e local significa aproximar a elaboração e a execução das políticas dos atores locais. Adota-se neste estudo a governança entendida como processo de descentralização do poder estatal para grupos compostos por representantes de diferentes segmentos da sociedade, além dos governos. Governança multinível, pois demanda articulação entre as esferas públicas e privadas e as lideranças locais, sobretudo, construção de agenda coletiva, consenso, articulação, visão regional e recursos técnicos e financeiros. Governança, nesse sentido, implica repartição da autoridade estatal e setorial. Na avaliação de Abdala (2007, p.93), a governança de "múltiplos atores pode resultar na constituição de acordos entre interesses econômicos de grandes corporações e comunidades [...]." Essas políticas buscam a distribuição "compartilhada de benefícios, a divisão de responsabilidades, cotas e acesso a recursos para diferentes consumidores visando a agregação de múltiplos interesses simultaneamente." Assim, discute-se governança com o objetivo de questionar as relações de poder na implementação da política pública de turismo e na concepção que os atores não governamentais têm papel importante na democratização da governança e na evolução da democracia e da cidadania. 
O tema governança se torna relevante na política pública de turismo e é conceito importante no planejamento de destinos turísticos. Parte dos estudos sobre governança enfatiza o papel do Estado na sociedade, principalmente, a relação entre a intervenção do Estado e autonomia social. O conceito abrangente da governança em termos de políticas públicas é a relação entre a intervenção do Estado como autoridade pública e a autonomia social ou autorregulação (HALL, 2011, p.14). O compartilhamento do poder é prática de difícil realização, tanto pelos governos que propõem, quanto pela sociedade, assim os instrumentos de governança precisam ser entendidos no contexto histórico. Entende-se a governança como instrumento de desenvolvimento político das regiões e dos destinos indutores. Os governos continuam a concentrar as políticas, assim conhecer os processos que propõem a governança é importante, pois permite identificar como o Estado atua na área de política de turismo (HALL, 2011, p.14). A sociedade organizada é território de interesses e valores diversos, entretanto, a necessidade de repartição do poder de decisão entre poder público e sociedade organizada é evidente. Regiões e municípios, muitas vezes, são receptáculos, não participam das decisões relativas ao processo de desenvolvimento. A governança é ponto chave para o desenvolvimento social, é meio e fim, portanto não é entendida nesta pesquisa apenas como vinculada à eficiência gerencial do sistema, pois a concepção não se restringe a governos eficientes, exige governos democráticos.

Toma-se a governança como proposta do Estado que pode ser desenvolvida pela sociedade na busca de politização. A sociedade com capacidade em atuar nos processos de desenvolvimento, portanto nos processos de concertação social como possibilidade de tornar regiões e municípios sujeitos. Mesmo que o poder da sociedade organizada territorialmente tenha limite, este não é desprezível, podendo-se vislumbrar no horizonte a possibilidade da prática de uma gestão territorial societária, apesar de o Estado ser um dos limites do poder da sociedade (DALLABRIDA, 2001). A experiência de governança na regionalização do turismo estudada nesta pesquisa se explica no contexto de uma política de governo. Considera-se a possibilidade da sociedade civil exercer poder e autoridade, o que apesar de não gerar mudança estrutural, é possibilidade de politização da sociedade. O estudo sobre diversas concepções 
ISSN: 1983-7151

de governança contribui para afirmar que governança pode ser entendida como efetivação do compartilhamento do poder do Estado com a sociedade organizada e sendo relação de poder é permeada de conflitos. Ocorre evolução conceitual nos estudos sobre governança e é consenso entre vários autores entender governança como a maneira pela qual o Estado tem atuado reduzindo a distância entre governantes e governados, incluindo relações intergovernamentais com diversos sujeitos, estruturas, processos e resultados.

A política de regionalização no turismo é proposta de intervenção e de descentralização que direciona a gestão do turismo e propõe articulação da sociedade por meio das instâncias de governança regional e local (grupo gestor do destino indutor) para desenvolver a regionalização, assim se estuda governança como forma de governar, processo e estrutura que estabelece a rede de governança da política nacional de turismo. A governança assume o papel de estratégia na condução das políticas públicas, de modo interorganizacional, uma faceta da teoria política, pois descreve certo tipo de relação entre o Estado e a sociedade (PETERS; PIERRE,1998). O Estado se reestrutura com o objetivo de "ser capaz de continuar a ser um veículo viável na busca do interesse coletivo em uma era de globalização da economia e aumento da dinâmica institucional e subnacional." O que explica estarem contando cada vez mais "com instrumentos de política bastante sutis em seu intercâmbio com a sociedade, mas isso não significa necessariamente que eles são menos eficientes nas técnicas coercitivas de direção" (PIERRE; PETERS, 2000, p. 196).

O conceito de governança admite diferentes significados e usos na produção acadêmica em Ciências Sociais. É a partir dos anos 1980 que o conceito se dissemina, sendo abordado em diversas áreas do saber: Rhodes (1996) afirma que governança é tema conhecido, mas impreciso e que é usado de diferentes maneiras, referindo-se ao Estado Mínimo, governança corporativa, New Public Management, "boa governança" e redes de trabalho autoorganizadas. Amplamente difundida em âmbito internacional, o conceito e a prática da governança são conhecidos no Brasil. Governança diz respeito "ao ato de governar, conduzir, reger" (MTur, 2008). Significa que institucionalizar as instâncias é "estabelecer organização para decidir e conduzir o desenvolvimento turístico de uma região" (MTur, 2007, p.14). A instância de governança regional 
é "organização com participação do poder público e dos atores privados dos municípios componentes das regiões turísticas, com o papel de coordenar o Programa em âmbito regional." Podem assumir diferentes estruturas e caráter jurídico, tais como: fóruns, conselhos, associações (MTUR, 2007, p.16). A governança na regionalização do turismo no Brasil proposta pelo Governo Federal envolve ação, direção e coordenação coletiva.

\section{A GOVERNANÇA LOCAL NA POLÍTICA DE REGIONALIZAÇÃO DO TURISMO: GRUPOS GESTORES NOS DESTINOS INDUTORES DO CEARÁ}

A proposta de governança do Governo Federal por meio do Programa de Regionalização do Turismo apresenta intenção de maior participação da população nas políticas públicas de turismo, dessa forma, a governança é "possibilidade de restaurar a legitimidade do sistema político pela criação de novos canais de participação e parcerias, contribuindo para novas formas democráticas de interação público-privada" (FREY, 2007, p.139). No âmbito da regionalização no turismo são definidos 65 destinos indutores do desenvolvimento turístico regional, inicia-se a realização do Relatório de Competitividade e são instituídas as instâncias de governança locais. $\mathrm{Na}$ primeira edição do relatório de competitividade foram realizados seminários nos destinos indutores para apresentação do Relatório e levantamento das ações prioritárias a partir dos resultados do índice de competitividade. Nesses seminários foram institucionalizados os grupos gestores.

A viabilização das funções atribuídas aos grupos gestores demanda intensa articulação com os gestores públicos. A efetivação da governança depende do estabelecimento de alianças, articulações, cooperação, visão de longo prazo e vontade política, tanto no âmbito regional, quanto no municipal e estadual. Foram elaboradas e repassadas orientações para formação do grupo gestor nos seminários de entrega dos resultados do relatório de competitividade. Os integrantes do grupo deviam pertencer à Instância de Governança Local, quando esta existir. Caso não existisse instância de governança local, o grupo deverá ser criado e incorporado à Instância quando esta for definida. E o grupo 
gestor deverá ter integrantes da iniciativa privada, poder público e terceiro setor. O grupo gestor devia compor o Conselho de Turismo ou outra instância local e ser tripartite. Os documentos que orientam a realização do Programa denotam a preocupação que as instâncias representem os diferentes setores da sociedade. O Ministério do Turismo desenvolveu as estratégias de apoio à realização do projeto "65 Destinos Indutores do Turismo", a exemplo do que foi feito nas regiões: disponibiliza assessoria especializada para o desenvolvimento do projeto e avança propondo um sistema de gestão com banco de dados para contribuir nas tomadas de decisão.

A participação nas instâncias de governança locais - grupos gestores configura-se como participação cujos indivíduos, organizados em grupo, são orientados a interferir e fazer com que o poder seja compartilhado, que os projetos não "caiam do céu tombando nas cabeças" dos residentes sem que esses tenham sido inseridos no contexto das decisões. Uma matriz orientadora para o trabalho dos grupos gestores era a lista de ações priorizadas a partir de resultados do primeiro relatório de competitividade. Viabilizar essas ações era uma das funções do grupo gestor. Esses grupos são unidades na diversidade, integram interesses diferentes e divergentes, no entanto, a politização nos destinos indutores pode significar mudanças nas sociedades locais.

A implantação do projeto "65 Destinos" contou com etapa de capacitação em gestão para os grupos gestores e outra do sistema de gestão do projeto. A etapa de capacitação contemplou quatro encontros nos quais foram tratados os temas liderança no planejamento, capacidade empreendedora e líder coach, liderança articuladora e inteligência competitiva (MTur, 2012, p. 24). Para o planejamento, a execução e o monitoramento das ações foram realizadas oficinas com os grupos gestores para capacitá-los na utilização do software Sistema de Gestão SG 65, a ferramenta colaborativa para o gerenciamento de atividades nos destinos indutores. De acordo com o MTur, o Estudo de competitividade, o sistema de informações e o projeto 'gestão de destinos' se integram e, a partir desse fluxo, o destino busca a competitividade planejando, mensurando, acompanhado ações e fortalecendo os grupos gestores e, consequentemente, a gestão do turismo.

Foram realizadas várias atividades com os grupos gestores do Ceará orientadas pelas consultorias contratadas pelo Ministério do Turismo: oficina 
sensibilização, Oficina Capacitação SG65, $3^{\text {a }}$ Pesquisa Estudo Competitividade e Workshops em 2009 e 2010, conforme relatórios da SETUR/Ceará. Também foram desenvolvidas atividades de capacitação e acompanhamento dos grupos gestores. No início de 2011, o Ministério do Turismo realizou o terceiro e último workshop - Liderança Articuladora e Inteligência Competitiva do Projeto de Gestão dos 65 Destinos Indutores e solicitou reunião de acompanhamento dos grupos. Os componentes dos grupos gestores representam diferentes e diversos segmentos da população residente, sendo o estabelecimento de consenso complexo, mas a participação de diferentes sujeitos nos grupos auxilia a tomada de decisão. O grupo gestor enfrentou o desafio de se organizar, se manter e se articular interna e externamente, mas as ações dependem dos poderes políticos e econômicos. No relatório que apresenta o índice de 2013 o MTur reitera, no âmbito da regionalização, o ator municipal: "Nesse processo de reestruturação, resgata-se a representação do ator municipal como agente de desenvolvimento, considerando-se ser ele o detentor de realidades e demandas locais [...] (MTur, 2013, p.24).

A existência dos grupos gestores ampliou o espaço da cidadania e a democratização do poder aproxima representantes da população das decisões que Ihes dizem respeito e incorpora na tomada de decisão a participação da comunidade, porém os governos não tiveram ação contínua e os grupos gestores não conseguiram se organizar. A proposta de organização de baixo, vinda pelo alto fica na retórica. Apesar de não serem grupos organizados pelas massas populares constituídos de baixo para cima, os grupos gestores são sujeitos políticos coletivos. A concepção de uma sociedade capaz de interferir nos processos decisórios oscila entre o compromisso daqueles que animam o processo permanentemente, da pouca flexibilidade de gestores públicos, descrédito das iniciativas públicas, inexistência de cultura voltada ao coletivo e ao enfrentamento às políticas.

Para Nogueira (2004), "tratar o Estado como algo neutro [...] é tão insuficiente quanto tratá-lo como encarnação viva do mal," e acrescenta que "o Estado precisa ser assimilado tanto como estrutura de dominação quanto como parâmetro ético de convivência e locus para o encontro de soluções positivas para os problemas sociais" (NOGUEIRA, 2004, p.61). O que se projeta para os destinos indutores é 


\section{ISSN: 1983-7151}

a cidadania, cujos protagonistas "concebem o mundo como um ambiente de direitos e de responsabilidades recíprocas e se realizam nele como sujeitos de vontade e de ação coletivamente construídos." A comunidade se apresenta como uma ordem política que "implica uma disposição nos indivíduos e nos grupos [...] para pensar o conjunto dos interesses, a correlação de forças, o governo, a dominação, as necessidades e as possibilidades. [...] essencialmente política dos cidadãos, em que a coerção e o conflito não se separam do consenso, o particular não se contrapõe ao geral, o privado não hostiliza o público." Dessa forma, não se cogita em torno de harmonia, parceria, pois não se separa política do antagonismo, da hostilidade (NOGUEIRA, 2004, p.62-63). Apesar "da autoorganização da sociedade organizada ser estimulada no projeto neoliberal orientada para a defesa de interesses corporativos, setoriais ou privatistas" (COUTINHO, 2000, p.98), a relação dialética colaboração- enfrentamento pode ser desenvolvida com o prosseguimento dos grupos e trazer benefícios para as populações residentes.

Com outra linha teórica, Araújo (2009) utiliza-se das teorias dos stakeholders e da teoria colaborativa no estudo do turismo. Esclarece que o envolvimento desses parceiros demanda a iniciativa de um convocador e que este pode ser qualquer um dos stakeholders. Na regionalização do turismo o convocador é o governo federal, por meio do Ministério do Turismo que propõe a colaboração com vistas à competitividade. Mas "a ideia central do fenômeno da colaboração é que organizações que se envolvem em arranjos colaborativos podem obter benefícios que não seriam possíveis ser obtidos se cada organização agisse de forma isolada" (ARAÚJO, 2009, p.63). A ideia central é fundamental no processo de efetivação da governança. Há uma série de desafios a superar: rivalidades municipais e regionais, competição política regional e municipal. A gestão do turismo não está articulada, o envolvimento dos stakeholders contribui para viabilizar as políticas, pois serão responsáveis nas localidades por parte da implementação. É participação e não legitimação de decisões tomadas. A participação de múltiplos stakeholders na elaboração de políticas públicas é orientação encontrada em instrumentos legais com respaldo no reconhecimento dos governos, das organizações não governamentais e da academia. Não garante harmonia, porém supõe decisões ponderadas em conjunto e não apenas por setores hegemônicos. Daí as "ações e políticas que emergem afetarão a 
estrutura de relações, de funcionamento e, em última instância, poderão gerar conflitos com outros stakeholders, envolvidos no ambiente mais amplo que compartilham" (ARAÚJO, 2009, p. 31). A governança como partilha de poder refere-se à participação não para legitimar decisões apresentadas pelos governos, mas para elaboração das decisões, deslocando o poder de decidir da esfera estatal em direção aos grupos constituídos, contudo isso não elimina o uso dessa organização na manutenção da hegemonia estatal por outra e também não impede que essa dinâmica contribua na socialização da política.

A proposta de governança na regionalização do turismo não se dissocia do Estado, inclusive a ausência deste é apontada como desmotivadora e desmobilizadora. Muitas das propostas elaboradas nos destinos demandam a ação estatal e os grupos gestores podem apenas articular e cobrar e não têm como resolver questões estruturais nos destinos indutores. As orientações para instalação das instâncias de governança levam a afirmar que o processo se orienta na construção de espaço público formado por sujeitos sociais ligados ao turismo na região, gerando descentralização de poder.

Os destinos indutores do desenvolvimento turístico regional são definidos como aqueles que dispõem de infraestrutura básica e turística e atrativos qualificados, que se caracterizam como núcleo receptor e/ou distribuidor de fluxos turísticos, capazes de atrair e/ou distribuir significativo número de turistas para o entorno e dinamizar a economia do território em que estão inseridos, conforme o Relatório Brasil (MTur, 2012, p.23). Os destinos indutores do desenvolvimento turístico regional do Ceará são Fortaleza, Aracati, Jijoca de Jericoacoara e Nova Olinda. Os grupos gestores desses destinos são constituídos por profissionais, empresários, governos, associações de classe, academia, lideranças comunitárias e se funcionassem a contento representariam avanço no compartilhamento do poder. A socialização da política, ou seja, o ingresso na esfera pública de um número cada vez maior de novos sujeitos políticos individuais e coletivos poderia ser impulsionadora para mudanças no fazer política e, consequentemente, na gestão dos destinos indutores do desenvolvimento turístico regional.

Os grupos gestores dos destinos indutores foram constituídos conforme as orientações estabelecidas pelo MTur com representantes dos governos, da 
iniciativa privada e do terceiro setor quando foi entregue pelo MTur/FGV e SEBRAE o primeiro relatório dos índices de competitividade no seminário realizado em cada destino no ano de 2008. Observa-se que a criação de novos grupos pode ser eficaz, pois dá oportunidades aos entrantes, propicia renovação, no entanto, grupos mais antigos desenvolveram alianças estratégicas que levam tempo para se firmar e que são importantes na viabilização do trabalho coletivo. A condução de certos projetos e experiências é explicada, em alguns casos, a partir das ideologias de partidos políticos. As políticas públicas carregam ideologias e visões de mundo, assim a gestão democrática aponta avanços e entraves e a organização da sociedade pode dificultar e/ou facilitar a manipulação dos grupos pelos atores hegemônicos. A participação não exclui problemas, inclusive nos próprios grupos. Combinar a ética solidária e comunitária com os interesses individuais, eis o grande desafio (COUTINHO, 2000, p. 144).

Participaram desta pesquisa representantes de diferentes segmentos dos grupos gestores e mais de $70 \%$ dos entrevistados participam dos grupos gestores desde 2008 e mais de $90 \%$ participavam ou ainda participam de outros grupos, ou seja, a maioria das pessoas está envolvida em outros processos participativos, o que significa que são engajadas politicamente. O que justifica também terem mencionado a dificuldade em participar, simultaneamente, das atividades da instância regional e da instância local, pois são as mesmas pessoas indicando a necessidade de compatibilização das agendas de trabalho das instâncias de governança regional e local e formação de novas lideranças. A definição dos componentes dos grupos foi feita entre participantes, inicialmente, dos Seminários de Competitividade realizados em 2008. O que se observa nos destinos indutores é o que acontece em vários lugares no Ceará. Geralmente são as mesmas pessoas que participam em diferentes grupos e esse número é pequeno. Em Fortaleza, o grupo gestor é uma célula do Fórum de Turismo do Ceará, que se originou do Pacto de Cooperação pelo Ceará, fundado com o objetivo de unir esforços para desenvolver ideias e influenciar na participação da comunidade no desenvolvimento do turismo sustentável no estado, portanto antecede à regionalização no turismo brasileiro. O Fórum e o Conselho Municipal de Turismo de Fortaleza se articulam entre si e se reúnem regularmente. São realizadas reuniões mensais na Assembleia Legislativa do Ceará e no SEBRAE-CE. 
Em entrevista à imprensa, um dos coordenadores do Fórum declara à imprensa local: "Como Instância de Governança o Fórum passa representar os poderes públicos e privados dos municípios que compõem a região turística, passando a realizar ações para operacionalizar o Programa de Regionalização do Turismo." Assevera que irão "atuar sabendo o que a ponta precisa e quer, ou seja, quais as demandas das entidades que fazem parte do Trade Turístico. Como Instância de Governança nosso papel será propor (enviar projetos), fiscalizar o que estiver sendo realizado e acompanhar essas ações [...]".

O Fórum do Turismo do Ceará foi institucionalizado pelo MTur como a primeira instância de Governança do Turismo Regional de Destino Indutor em capital do Brasil em três de março de 2009. O grupo gestor do destino Fortaleza elaborou o regimento interno, em que se define como Grupo Gestor de Fortaleza - Destino Indutor de Desenvolvimento Turístico Regional, criado em 2008, na primeira etapa de realização do Estudo de Competitividade dos 65 Destinos, promovido pelo Ministério do Turismo em parceria com o SEBRAE e a Fundação Getúlio Vargas. Neste regimento lê-se que o grupo de trabalho congrega representantes da esfera pública, privada e sociedade civil, as quais representam os diversos setores que compõem a cadeia turística. Conforme o regimento interno, a finalidade do Grupo é: auxiliar e monitorar a governança da Gestão do Destino Indutor Fortaleza e dar continuidade aos trabalhos de desenvolvimento utilizando para isso o "Estudo de Competitividade dos 65 Destinos Indutores do Desenvolvimento Turístico Regional." O objetivo do grupo é: acompanhar o processo de gestão do destino, elegendo prioridades, indicando propostas de ações e projetos e monitorando os planejamentos e as ações realizadas.

Em Nova Olinda, teve-se acesso às atas de reuniões do Grupo Gestor nos anos de 2008, 2009, 2010 e 2011. Em uma das reuniões em 2009 há a informação da criação do Conselho Municipal de Cultura e Turismo e discute-se que o Conselho se reúna junto com o grupo gestor. A existência de dois grupos não é considerada superposição. Em junho de 2013, procede-se à recriação do Grupo Gestor. Em algumas atas é mencionado que ser Destino Indutor tem auxiliado o município a obter verbas e menciona-se a execução do projeto de calçamento da sede, por exemplo. Na região do Cariri, onde se localiza Nova Olinda, observou-se que, na instância regional, o Fórum de Turismo e Cultura é atuante e realiza reuniões 
itinerantes. Em Jijoca de Jericoacoara é realizada reunião em junho de 2011, nela a pauta inclui: recomposição do grupo gestor, índice de competitividade do turismo nacional, ações propostas para o destino, plano de ação, inserção das ações no sistema de gestão 65 e calendário de reuniões 2011.

Verificou-se que houve uma dinâmica dos grupos gestores, que se articularam local e regionalmente, Nesse sentido, observou-se a tendência dos entrevistados de vincular maior eficiência dos grupos ao envolvimento dos secretários municipais e/ou respeito destes aos grupos. Foram relatadas experiências cujo secretário se integrava, discutia e ouvia o grupo e animava o processo. Entende-se que essa tendência está ligada ao fato da execução de muitas ações dependerem do poder público, se não da pasta do turismo, da articulação desta com outras pastas no município, com o Prefeito Municipal e o governo estadual e/ou federal. Revela também a necessidade de desenvolver mais a autogestão dos grupos que precisam ser institucionalizados, fortalecidos e reconhecidos no sistema de gestão dos governos. O apoio do Prefeito e a atuação do secretário municipal de turismo dialogando e trabalhando com o grupo foram itens associados ao bom desempenho dos grupos, pois se o Prefeito não prioriza o turismo, pouco ou nada se faz.

Nas entrevistas foi evidenciada a desarticulação dos grupos gestores: Até a gestão passada quem tomava as decisões era o secretário, agora não sei quem é, afirma um participante. A ideia que o entrevistado passou não foi de decisões arbitrárias pelo secretário anterior, mas de envolvimento, em particular com o desenvolvimento dos trabalhos da regionalização, em contraposição à situação vivenciada no momento da entrevista.Integrantes dos grupos continuam atuando nos segmentos que estão ligados (associações profissionais e empresariais) e/ou outros grupos como conselhos municipais e instâncias regionais. Entrevistados expressaram em vários momentos reconhecimento à atuação de secretários municipais que mantiveram diálogo com os grupos, levaram em consideração propostas e posições levantadas pelos grupos gestores, foram proativos e demonstraram compromisso. O que significa que os entrevistados avaliam e reconhecem gestores articuladores que atuam como líderes animando o processo. Foi mencionado também o quanto é prejudicial aos grupos quando o secretário não se envolve, não tem conhecimento da situação do turismo 
no município e não dialoga com esses representantes. Alguns entrevistados afirmam que é positivo o secretário ser o presidente do grupo e a participação do poder público é entendida como facilitadora para execução das ações. Os entrevistados informaram que, a partir de 2011, a dinâmica dos grupos se arrefece em razão da desmobilização no MTur e ambiência que antecede às eleições municipais, lançando dúvidas sobre a continuidade do trabalho. Um fator considerado facilitador foi Prefeito e Secretário pertencerem ao mesmo partido. A desarticulação dos grupos também é expressa: O grupo não se reúne há mais de um ano. O regimento interno diz na primeira terça-feira do mês, mas ninguém vai. Vamos perder verba, pois não há mais mobilização. Em 2011 houve desmobilização, total desinteresse. Tudo desmontado.

Sobre quem exerce influência na tomada de decisão relacionada ao turismo na cidade, os representantes dos grupos têm o esclarecimento sobre o direito de opinar e não apenas de apoiar propostas governamentais. Avaliam que o respeito ao grupo gestor varia em função da postura, principalmente, dos gestores públicos. Os resultados da pesquisa demonstram que, na visão dos representantes, os grupos gestores não alcançaram posição de destaque no processo de tomada de decisão relacionada ao turismo. Dada a situação de desmobilização, fica evidenciada a comparação quando perguntados se o Grupo Gestor influenciava na política pública: Na gestão anterior sim, atualmente não. É a resposta obtida.

A estruturação dos grupos gestores é forma organizada de participação, particulariza a participação que não é dos cidadãos em geral, embora não impeça a participação destes. O arranjo de governança suscita o debate sobre descentralização, participação, legalidade e legitimidade, pois os representantes da sociedade nos grupos de governança não são eleitos pela população, o que para alguns fere princípios democráticos. Abre-se espaço para discutir a legitimidade da composição dos grupos e discutir o processo de formação dos grupos. A instância regional é vista como instância que deve operacionalizar a integração regional, operacionalização esta tida como inexistente como ação dos grupos gestores. Nesse contexto, é mencionada a Rota das Emoções como incentivadora da regionalização. Nos grupos estudados não houve consulta social mais ampla para formação dos grupos, os representantes foram definidos, 
inicialmente, pela inserção da área no turismo (hotelaria, receptivo, gestão pública) com a preocupação de englobar os setores público e privado e a sociedade civil organizada. A análise dos dados da pesquisa permite afirmar que a atuação do grupo passa pela necessidade de desenvolver liderança e fortalecer o grupo, inserindo-o de fato no sistema de gestão e obtendo assim respaldo do poder público. Esses itens não estão separados, mas inter-relacionados.

Muitos desafios se apresentaram aos grupos gestores, mas a existência do grupo é considerada importante por promover a gestão compartilhada com a participação de diversos atores sociais, conduzindo à outra forma de gestão. A heterogeneidade é tida como positiva, promovendo capacidade técnica, empresarial e social que pode contribuir com a formatação e a implementação de projetos estratégicos para o município e região. A maioria dos participantes da pesquisa mora no destino indutor e está inserida diretamente na atividade turística e comunica a preocupação por um turismo de qualidade. A grande demanda é que os grupos gestores sejam ouvidos, que as ações sejam concretizadas e que haja retorno por parte dos gestores públicos. O turismo é analisado como atividade que promove o desenvolvimento dessas localidades, mas que precisa ser orientado na busca de desenvolvimento sustentável. A gestão precisa desenvolver a visão do turismo e a cidade - paraíso decantado para os turistas - ser vivenciada pelos residentes.

Apesar do pouco tempo de existência, os grupos gestores foram importantes. A promoção de debates, a identificação de problemas, a indicação de soluções e os encaminhamentos para as políticas públicas, trabalhar com outros grupos como Conselho Comunitário, Conselho Municipal da Cultura, tudo isso é avaliado como maior democratização da importância do turismo para a sociedade local. Dessa forma, o grupo gestor contribui para a discussão de projetos para o município, muitos deles com repercussão no turismo regional e instituições participantes intensificam suas ações em função das informações trabalhadas nas reuniões, dos projetos e dos indicadores de competitividade que são divulgados.

Os membros de uma instância de governança precisam de tempo para desenvolver sinergia, compromissos. Alerta Bauman (2003) que uma comunidade ética "Teria que ser tecida de compromissos de longo prazo, de direitos inalienáveis e obrigações inabaláveis, que, graças à sua durabilidade 
prevista (melhor ainda, institucionalmente garantida), pudesse ser tratada como variável dada no planejamento e nos projetos de futuro" (BAUMAN, 2003, p. 68). Os grupos gestores no período estudado não tiveram esse tempo e, provavelmente, o apoio necessário, pois a efetivação da governança se dá em um campo de luta. Os grupos gestores foram definidos pelo MTur que os autoriza a representar a coletividade. A orientação de composição dos grupos estabelece que seja tripartite (público, privado, terceiro setor), mas lembra Bobbio (1984, p. 20) que: "é preciso que aqueles que são chamados a decidir ou a eleger os que deverão decidir sejam colocados diante de alternativas reais e postos em condição de poder escolher entre uma e outra." Muitos dos entrevistados mencionaram que é muita reunião e pouca realização. A estratégia de criação de grupos movimenta os locais, mas os grupos não se sustentaram, a condição de decidir e de interferir foi insuficiente e descontínua. A questão não se resolve apenas na preparação de líderes, que, apesar de necessária, passa pela necessidade de uma forma de organização capaz de concretizar não apenas a participação, mas a efetivação da governança com a realização de ações apontadas pelos grupos.

Participar requer abdicar de um tempo para si e encontrar tempo para o coletivo. "Aquele que participa não o faz sem ônus, sem algum 'sacrifício'. Quando esse ônus cresce demais, a participação reflui." Além do mais, nem sempre os resultados são imediatos ou com a dimensão esperada. Para que a gestão participativa aconteça de fato, é necessário contar com "decisões e orientações governamentais claras: projetos nítidos, consistentes e adequadamente comunicados" (NOGUEIRA, 2004, p.153-155) e com a população disposta a participar, a reivindicar e gestores públicos capazes de contribuir, efetivamente, nos processos de governança. Ideal seriam os grupos pautarem os governos. Como salienta Nogueira (2004, p. 151): "A sociedade civil persiste com seu potencial inexplorado (ou mal explorado), e temos como patrimônio uma rica experiência de unidade e luta democrática, que já provou sua eficácia e nos ajudou a dar justo valor a política, ao pluralismo, à cidadania." O poder público faz chamamento, investe, inicia a mobilização. Estados e Municípios participam com níveis de interesse diferenciados, em seguida, há interrupção. No contexto local, os grupos vivenciaram eleições, há desarticulação, não se sabe se o projeto terá prosseguimento e em qual orientação, resultado: desmobilização e descrédito. 


\section{CONSIDERAÇÕES FINAIS}

Governança na política de regionalização no turismo significa descentralização, transferência de poder decisório. Movimento contrário não resolve problemas estruturais no entanto, é prática de difícil concretização. A organização da sociedade é o passo com o qual se estabelecem políticas públicas mais condizentes com as aspirações das populações. Assim, uma vez falar em transformação, mas não conseguir esboçar como e aonde se chegará, podendo se tornar discurso vazio, privilegia-se a via em que a governança traz a perspectiva institucional e não subtrai o Estado, fortalece a política, diminui a distância entre governo e governados, melhora a atuação do Estado, reforça a cidadania, efetiva a política pública oriunda da sociedade organizada e na qual a organização local interfere na forma como se dá o desenvolvimento. Pensar o turismo como proposta de desenvolvimento social torna possível outro turismo. Parte-se da particularidade da organização no turismo para a universalidade de modelo de desenvolvimento e vice-versa. A relação entre sociedade capitalista e forma sustentável de turismo como fator de desenvolvimento social tem no controle da sociedade instrumento a favor da premissa do turismo como fator de desenvolvimento e de inserção social. É condição para que a proposta de governança não assuma apenas carga retórica.

Os destinos indutores no Ceará: Fortaleza, Aracati, Jijoca de Jericoacoara e Nova Olinda carecem de serviços básicos, inclusive a metrópole Fortaleza, a despeito de muitos investimentos já terem sido realizados. Esses destinos enfrentam problemas, alguns agravados pela dinâmica do turismo. Assim o esforço primeiro é na resolução de problemas internos. Com o estudo da governança na política de regionalização nos destinos indutores do desenvolvimento turístico regional, verifica-se que há grande assimetria entre implantação de equipamentos e serviços e efetivação da regionalização e da governança. O turismo avança no Ceará com a implantação de equipamentos e a oferta de serviços, mas a governança pouco tem avançado na gestão do turismo, apesar de ser preconizada nos Planos Nacionais há mais de uma década. O incremento do turismo é intenso e desigual, enquanto o incremento 
do compartilhamento do poder entre governos, sociedade organizada e população residente é incipiente.

No Ceará, os grupos gestores não ganham impulso e não conseguem estabelecer vínculos fortes entre si e com as forças políticas. A instituição de um novo grupo não ocasionou a operacionalização de muitas das reivindicações levantadas a partir do relatório de competitividade, nem mesmo a articulação de um grupo gestor coeso e forte. Os municípios não se apropriaram das ferramentas disponibilizadas sob a tutela do MTur, porém grupos e lideranças constituídos, anteriormente, continuam atuando, são grupos que aglutinam as pessoas, mas não se reconhecendo e/ou denominando como grupo gestor. A efetivação da governança demanda mudança na gestão dos governos. Anunciar a descentralização, fomentar a participação não é o mesmo que efetivar o compartilhamento do poder, ou seja, a governança. A descentralização ainda é contemplada, significativamente, nos discursos. Os grupos gestores conseguem articular algumas ações regionais na promoção e na estruturação de produtos, mas não ocorrem mudanças substantivas nas regiões e nem nos destinos indutores. Apesar de a política pública anunciar a governança, estimular e apoiar as Unidades da Federação, a ausência do agente promotor causa desmobilização e descrédito. Promover a governança como partilha de poder com a sociedade é movimento contrário na sociedade de classe.

A dinâmica política interfere e os núcleos indutores têm também conflitos internos: diferenças políticas e partidárias, questões particulares, ideologias e interesses. As mudanças políticas locais levam a estagnação como se tudo parasse até novos gestores assumirem os postos. O que se explica pelo fato que as pessoas mobilizadas nos municípios entendem que precisam do gestor local para dar continuidade aos trabalhos. De fato, os grupos gestores não têm recursos e legitimidade para executar ações, são antes articuladores e articulados nas áreas em que atuam. Esses grupos precisam de mais tempo e apoio técnico que se traduz como apoio político para viabilizar os trabalhos. A desarticulação dos grupos gestores assinala a necessidade de desenvolver mais a autogestão dos grupos que precisam ser institucionalizados, fortalecidos e reconhecidos no sistema de gestão dos governos. A delegação de poderes do Ministério do Turismo às instâncias de governança diz respeito não apenas ao MTur, mas 
também aos governos municipais e estaduais que, no entanto, são autônomos. O exercício e a efetivação da governança não são arena de harmonia, mas de conflitos e de construção de objetivos comuns. Nas regiões e nos destinos indutores estão indivíduos e grupos mais fortes e mais fracos. A efetivação da governança exige mudança na forma de fazer política e na administração pública, envolve mudança na postura dos administradores públicos, dos empresários e da população para viabilizá-la. A ação dos grupos depende da posição dos governantes de aceitarem o compartilhamento do poder como modo de funcionamento da gestão pública. Em um raciocínio otimista, o funcionamento dos grupos gestores pode culminar em desenvolvimento político abrangente de pessoas que discutem questões importantes em um destino turístico, portanto, complexidade que engloba assuntos desde saúde, educação, infraestrutura e qualificação profissional, movimento com agenda densa.

Dessa forma, obter transformações na governança ligada ao turismo engendra mudanças mais amplas na e da sociedade. A resolução de problemas discutidos na esfera do turismo, muitas vezes, significa lidar com problemas estruturais recorrentes. A efetividade dos grupos gestores não significa eliminação de todos os problemas; no melhor dos mundos significaria resoluções de maior interesse das comunidades. No entanto, a governança pretendida não diz respeito apenas ao turismo, mas à sociedade. Organizações como as do grupo gestor fortalecem o processo democrático e podem gerar ações públicas mais condizentes com as expectativas dos residentes e contribuir para a socialização da política. A reestruturação da política de regionalização passa pelo fortalecimento da organização municipal e regional. Os grupos gestores, apesar das dificuldades internas e externas, mostram que é possível avançar na governança, mas que há necessidade de apoio ao processo de estruturação dos grupose, especialmente, compromisso do poder público com as deliberações das instâncias de governança que deveriam estar envolvidas na tomada de decisão. As lideranças locais respondem positivamente à proposta de regionalização e de governança, mas a efetivação da regionalização e da governança necessita de direcionamento e de realizações, não podendo ficar apenas em discursos. A estrutura de governança proposta implica compatibilizar a autonomia das instâncias de governança e legitimar politicamente esses sujeitos e definir 
instrumentos que dificultem a mudança de encaminhamento da organização da governança a cada eleição.

Os grupos gestores foram instituídos para descentralizar o poder de decisão relacionado ao turismo, mas na prática não conseguem efetivar as ações pretendidas. Assim a descentralização do poder de decisão não se efetiva. Os grupos gestores dos destinos indutores são instituídos, mas não se mantêm articulados e pouco contribuem para o desenvolvimento do turismo nas regiões do Ceará. As indicações de desenvolvimento da regionalização e da efetivação da governança nos destinos indutores no Ceará são incipientes. Há que ser retomado o investimento nas instâncias de governança locais e regionais com o objetivo de promover o ciclo virtuoso na vida política, fortalecendo as instâncias de governança que deverão articular a funcionalidade do índice de competitividade.

\section{REFERÊNCIAS}

ABDALA, Fábio A. Governança global sobre florestas: o caso do programa piloto para proteção das florestas tropicais do Brasil.1992/2006. Brasília, 2007. Tese (Doutorado em Relações Internacionais). 320f. Programa de Pós- Graduação em Relações Internacionais, Universidade de Brasília, Brasília-DF, 2007.

AHRENS, Joachim. Governance in the process of economic transformation. Draft version, Apr. 2006.

ARAÚJO, Lindemberg M. Planejamento Turístico Regional: Participação, parcerias e sustentabilidade. Maceió: EDUFAL, 2009.

BAUMAN, Zygmunt. Comunidade: a busca por segurança no mundo atual. Rio de Janeiro: Jorge Zahar Ed., 2003.

BEVIR, Mark. Governança Democrática: uma Genealogia. Revista de Sociologia e Política. Curitiba, v. 19, n. 39, p. 103-114, jun. 2011.

BOBBIO, Norberto. 0 futuro da democracia. Uma defesa das regras do jogo. $6^{a}$ edição. Tradução de Marco Aurélio Nogueira. Rio de Janeiro: Paz e Terra, 1986.

BRASIL. Ministério do Turismo. Índice de competitividade do Turismo Nacional. Destinos indutores do desenvolvimento turístico regional. Relatório Brasil. 2013. Brasília, 2013.

BRASIL. Ministério do Turismo. Coordenação Geral de Regionalização. Institucionalização das instâncias de governança regional. Brasília, 2007. 
BRASIL. Ministério do Turismo. Material didático do Programa de Regionalização do Turismo. Módulo Operacional 3 - Institucionalização da Instância de Governança Regional. MTur, 2008.

CAREgnATO, Rita C. A., MUTTI, Regina. Pesquisa qualitativa: análise de discurso versus análise de conteúdo. Florianópolis, 2006 out-dez; 15(4): 679-84.

COUTINHO, Carlos N. Contra a corrente. Ensaios sobre democracia e socialismo. São Paulo, Cortez, 2000.

DALLABRIDA, Valdir R. A gestão societária do processo de Desenvolvimento Local/Regional. In: REA-Revista de Estudos da Administração, ano 2, nº 3, (RS), 2001.

DALLABRIDA, Valdir R. A Gestão Social dos Territórios nos Processos de Desenvolvimento Territorial: Uma Aproximação Conceitual. Sociedade, Contabilidade e Gestão, Rio de Janeiro, v. 2, n. 2, 2007. Origem: RS.

DAVIES, Jonathan S. Challenging Governance Theory: theory from networks to hegemony. Distributed for Policy Press at the University of Bristol Edição: 2011.

FREY, Klaus. Governança Urbana e Participação Pública. P.RAC-Eletrônica, v. 1, n. 1, art. 9, p. 136-150, Jan./Abr. 2007. Disponível em: http://www.anpad.org.br/rac-e. Acesso em: 11 nov. 2013.

HALL, Collin Michael. A typology of governance and its implications for tourism policyanalysis. 2011.

KERSBERGEN, Kees V.; WAARDEN, Frans V. Governance' as a bridge between disciplines: Cross-disciplinary inspiration regarding shifts in governance and problems of governability, accountability and legitimacy. European Journal of Political Research, 2004.

KOOIMAN, J. Governing as Governance. Thousand Oaks, California: SAGE Publications Ltd. 2003.

LORRAIN, Dominique. Annales de la recherche urbaine, janvier ,1982. Administrer, gouverner, réguler.

MATIAS-PEREIRA, José. Manual de gestão pública contemporânea, São Paulo: Atlas, 2010.

MILANI, Carlos; SOLINÍS, Germán. Pensar a democracia na governança mundial: algumas pistas para o futuro. In: MILANI, Carlos; ARTURI, Carlos; SOLINÍS, Germán (Orgs.). Democracia e Governança Mundial: que regulações para o século XXI? 2002. 
NOGUEIRA, Marco A. Um Estado para a sociedade civil: temas éticos e políticos da gestão democrática. São Paulo: Cortez, 2004.

PIERRE, Jon; PETERS, B.Guy. Governance, Politics and the State. London: Palgrave Macmilan, 2000.

PETERS, B. G; PIERRE, J. "Governance Without Government? Rethinking Public Administration." Journal of Public Administration Research and Theory, Vol. 8, No. 2:223-243. 1998.

RHODES, R. A. W. The New Governance: Governing Without Government. Political Studies, XLIV, vol. 44, n4, p. 652-667, 1996.

ROBICHAU, Robbie W. The Mosaic of Governance: Creating a Picture with Definitions, Theories, and Debates. 2011.

STOKER, Gerry. Governance as theory: five propositions. International Social Science Journal, v. 50. p. 17-28, 1998. 